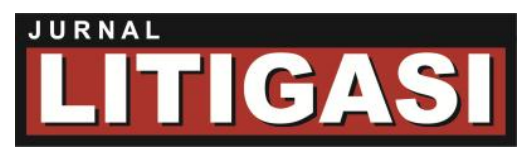

Available online at: http://ejournal.unpas.ac.id/index.php/litigasi

Litigasi, Vol. 16(2), 2015, 2875-2905

DOI: http://dx.doi.org/10.23969/litigasi.v16i2.37

\title{
PENYERAPAN ISTILAH ASING PADA TERMINOLOGI HUKUM DI INDONESIA
}

\author{
Ira Thania Rasjidi \\ Mahasiswa Program Doktor Ilmu Hukum Fakultas Hukum Universitas Padjadjaran Bandung, Jl. \\ Banda No. 40 Bandung Telp. (022) 4220696, Fax. (022) 4220696, Email: \\ ira.thania123@gmail.com.
}

\begin{abstract}
ABSTRAK
Penyerapan istilah dan terminologi asing sampai saat ini menjadi masalah karena tidak disesuaikan dengan kaidah bahasa Indonesia yang disempurnakan (EYD). Selain itu bahasa hukumnya bersifat kaku dan multitafsir. Dengan menggunakan metode penelitian hukum normatif dianalisis data-data yang diperoleh dari perpustakaan. Hasilnya, penyerapan istilah asing dapat diterima, memudahkan hubungan dalam pergaulan internasional.
\end{abstract}

Kata Kunci: Serapan; Terminologi; Hukum; Istilah; Asing

\begin{abstract}
Absorption of foreign terms and terminology of today become a problem because it is not adapted to the rules of Indonesian enhanced (EYD). Additionally rigid legal language and multiple interpretations.

By using the method of normative legal research analyzed data that was obtained from the library. As a result, the absorption of foreign terms are acceptable, facilitate relations in the international arena.
\end{abstract}

Keyword: Absorption; Terminology; Legal; Glossary; Foreign

Copyright (C) 2015, LITIGASI, p-ISSN: 0853-7100; e-ISSN: 2442-2274 
Available online at: http://ejournal.unpas.ac.id/index.php/litigasi

Litigasi, Vol. 16(2), 2015, 2875-2905

DOI: http://dx.doi.org/10.23969/litigasi.v16i2.37

\section{PENDAHULUAN}

Bahasa adalah kata-kata yang digunakan sebagai alat manusia untuk menyatakan atau melukiskan suatu kehendak, pikiran, pengalaman, terutama dalam hubungannya dengan manusia lain. Bahasa yang dipergunakan dalam dunia ilmu pengetahuan disebut bahasa ilmiah atau bahasa keilmuan.

Bahasa Indonesia sekarang sudah menjadi bahasa modern, yang awalnya merupakan dan berakar dari bahasa Melayu, yang kemudian berkembang dan bertambah karena kebutuhan berinteraksi dengan bahasa asing yang di Indonesiakan atau bahasa asing yang menjadi istilah-istilah baru. Terjadinya masukan bahasa asing sudah sejak lama, sejak masuknya agama Hindu, Islam atau masuknya orang Eropa, terutama Belanda yang menjajah Indonesia selama 350 tahun. Masuknya pengaruh bahasa Belanda tidak hanya kepada bahasa umum di Indonesia tetapi juga sangat kelihatan dalam bahasa hukum, karena sebelum kemerdekaan, bahasa hukum yang dipergunakan adalah bahasa Hukum Belanda, atau terjemahannya dari hukum yang dibuat dalam bahasa Belanda atau bahasa hukum Belanda yang di Indonesiakan. Sehingga 'semantik' bahasa hukum Indonesia lebih banyak berlatar belakang kesenian hukum, pengetahuan hukum dan filsafat hukum Belanda yang dipengaruhi hukum Romawi dan Kristen.

Semantik Hukum adalah ilmu pengetahuan hukum yang menyelidiki makna atau arti kata-kata hukum, perhubungan dan perubahan arti kata-kata itu dari zaman ke zaman menurut waktu tempat dan keadaan. Misalnya istilah Hukum Perdata adalah terjemahan dari istilah hukum Belanda yaitu 'privaatrecht', dan

Copyright ( 2015 , LITIGASI, p-ISSN: 0853-7100; e-ISSN: 2442-2274 
hukum sendiri adalah serapan dari bahasa Arab yaitu Hukum, dan perdata adalah serapan dari bahasa Hindu yaitu 'prodata' (Hilman Hadikusuma, SH, 1983 : 810).

Saat ini sedang popular istilah hak prerogatif seorang presiden misalnya untuk menentukan hukuman seseorang apakah terhukum bisa mendapatkan grasi atau tidak, mengangkat seorang menteri atau suatu lembaga tertentu di pemerintahannya. Prerogatif (bahasa Latin: praerogatio, -onis) diartikan hak lebih tinggi (diberi preferensi) dalam makna hukumnya.; atau di dalam bahasa Inggris: prerogative; dan menurut bahasa Jerman: das Vorrecht; "hak istimewa"). Dalam istilah hukum, hak prerogative merupakan hak khusus atau istimewa yang diberikan kepada pemerintah atau penguasa suatu negara dan diberikan kepada seorang atau sekelompok orang, yang terpisah dari hak-hak masyarakat menurut hukum yang berlaku.

Kata atau istilah prerogative merupakan kata serapan, kata yang berasal dari bahasa asing yang sudah diintegrasikan ke dalam suatu bahasa dan diterima pemakaiannya secara umum dari saat ini di masyarakat telah banyak menggunakan kata-kata serapan, mereka berpendapat bahwa menggunakan kata - kata serapan adalah suatu hal yang dapat menjadikan mereka sebagai orang yang terpelajar, gaul, modern dan lain-lain.

Kata serapan adalah kata yang berasal dari bahasa lain (bahasa daerah/bahasa luar negeri) yang kemudian ejaan, ucapan, dan tulisannya disesuaikan dengan penuturan masyarakat Indonesia untuk memperkaya kosa kata. Setiap masyarakat

Copyright @ 2015, LITIGASI, p-ISSN: 0853-7100; e-ISSN: 2442-2274 
bahasa memiliki tentang cara yang digunakan untuk mengungkapkan gagasan dan perasaan atau untuk menyebutkan atau mengacu ke benda-benda di sekitarnya. Hingga pada suatu titik waktu, yang sering dianggap lebih mudah adalah mengambil kata yang digunakan oleh masyarakat luar yang menjadi asal hal ihwal baru itu.

Kata Terminologi juga pada judul di atas juga merupakan kata serapan.Terminologi (bahasa Latin: terminus) atau peristilahan adalah ilmu tentang istilah dan penggunaannya, adalah kata dan gabungan kata yang digunakan dalam konteks tertentu. Proses pembentukan istilah dimulai dengan pemadanan atau penerjemahan, misalnya "camera" menjadi kamera; dan gabungan penerjemahan dan penyerapan, misalnya subdivision menjadi subbagian.

Penyerapan istilah asing dapat saja diterima, dan tidak dapat dicegah antara lain demi kemudahan pengalihan antar-bahasa dan keperluan masa depan, pemasukan istilah asing, yang bersifat internasional, melalui proses penyerapan dapat dipertimbangkan jika salah satu syarat atau lebih yang berikut ini dipenuhi :

a. Istilah serapan yang di pilih lebih cocok karena konotasinya;

b. Istilah serapan yang di pilih lebih singkat jika dibandingkan dengan terjemahan Indonesianya.

c. istilah serapan yang dipilih dapat mempermudah tercapainya kesepakatan jika istilah Indonesia terlalu banyak sinonimnya.

d. Istilah serapan yang dipilih dapat membantu dalam menterjemahkan istilah-istilah hukum untuk menyamakan presepsi.

Copyright ( 2015 , LITIGASI, p-ISSN: 0853-7100; e-ISSN: 2442-2274 
Available online at: http://ejournal.unpas.ac.id/index.php/litigasi

Litigasi, Vol. 16(2), 2015, 2875-2905

DOI: http://dx.doi.org/10.23969/litigasi.v16i2.37

Berdasarkan uraian tersebut, maka dalam penelitian ini akan dibatasi masalahmasalah sebagai berikut:

1. Apakah penyerapan istilah asing merupakan hal yang lazim dan dapat diterima pada setiap Negara?

2. Bagaimana manfaat penyerapan tersebut dalam hubungan/pergaulan internasional?

3. Bagaimana bagi dunia pendidikan adakah manfaat terjadinya penyerapan tersebut?

4. Apakah bahasa serapan itu dapat merusak kaidah bahasa Indonesia ?

5. Apakah penggunaan bahasa serapan asing dalam terminologi hukum Indonesia sebagai hal yang sah-sah saja?

\section{METODE PENELITIAN}

Jenis penelitian deskriptif analitis, data disimpulkan dengan dianalisis secara kritikal dan argumentatif. Pendekatannya yuridis normatlf, data dipungut di perpustakaan : bahan hukum primer, sekunder dan tertier. Analisis data; yuridis kualitatif, tanpa statistik dan matematik.

\section{HASIL PENELITIAN DAN ANALISIS}

Seperti telah dibahas sebelumnya bahwa bahasa Indonesia tidak hanya terdiri dari bahasa murni asli Indonesia saja. Dalam perkembangannya, bahasa Indonesia juga menyerap unsur dari pelbagai bahasa lain, baik bahasa daerah

Copyright (C) 2015, LITIGASI, p-ISSN: 0853-7100; e-ISSN: 2442-2274 
maupun bahasa asing, seperti Sanskerta, Arab, Portugis, Belanda, Inggris, Perancis atau pun Jerman.

Soal kata serapan dalam bahasa atau lebih tepatnya antar bahasa adalah merupakan suatu hal yang lumrah. Setiap kali ada kontak bahasa lewat pemakainya pasti akan terjadi serap menyerap kata.

Unit bahasa dan struktur bahasa itu ada yang bersifat tertutup dan terbuka bagi pengaruh bahasa lain. Tertutup berarti sulit menerima pengaruh, terbuka berarti mudah menerima pengaruh.

Bunyi bahasa dan kosa kata pada umumnya merupakan unsur bahasa yang bersifat terbuka, dengan sendirinya dalam kontak bahasa akan terjadi saling pengaruh, saling meminjam atau menyerap unsur asing. Peminjaman ini dilatar belakangi oleh berbagai hat antara lain kebutuhan, prestise kurang faham terhadap bahasa sendiri atau berbagai tatar belakang yang lain.

Tidak ada dua bahasa yang sama persis apalagi bahasa yang berlainan rumpun. Dalam proses penyerapan dari bahasa pemberi pengaruh kepada bahasa penerima pengaruh akan terjadi perubahan-perubahan. Ada proses penyerapan yang terjadi secara utuh, ada proses penyerapan yang terjadi dengan beberapa penyesuaian baik yang terjadi dalam bahasa lisan maupun bahasa tulis. Dalam penyesuaian itu akan terjadi, pergeseran baik dalam ucapan maupun ejaan antar bahasa pemberi dan penerima pengaruh maupun pergeseran semantis.

Masuknya unsur-unsur asing ini secara historis juga sejalan dengan kontak budaya antara bangsa Indonesia dengan bangsa-bangsa pemberi pengaruh. Mula-

Copyright @ 2015, LITIGASI, p-ISSN: 0853-7100; e-ISSN: 2442-2274 
mula bahasa Sansekerta sejalan dengan masuknya agama Hindu ke Indonesia sejak sebelum bahasa Indonesia memunculkan identitas dirinya sebagai bahasa Indonesia, kemudian bahasa Arab karena eratnya hubungan keagamaan dan perdagangan antara masyarakat timur tengah dengan bangsa Indonesia, lalu bahasa Belanda sejalan dengan masuknya penjajahan Belanda ke Indonesia, kemudian bahasa Inggris yang berjalan hingga sekarang, salah satu faktor penyebabnya adalah semakin intensifnya hubungan ilmu pengetahuan dan teknologi antara bangsa Indonesia dengan masyarakat pengguna bahasa Inggris.

Berdasarkan taraf integrasinya, unsur serapan dalam bahasa Indonesia dapat dibagi atas dua golongan besar yaitu:

Pertama, unsur serapan yang belum sepenuhnya terserap ke dalam bahasa Indonesia, seperti reshuffle, shuttle cock, l'exploitation del'homme par I'homme. Unsur-unsur ini dipakai dalam konteks bahasa Indonesia, tetapi pengucapannya masih mengikuti cara asing.

Kedua, unsur serapan yang pengucapan dan penulisannya disesuaikan dengan kaidah bahasa Indonesia. Dalam hal ini diusahakan agar ejaannya hanya diubah seperlunya sehingga bentuk Indonesianya masih dapat dibandingkan dengan bentuk asalnya. Misalnya saja central menjadi sentral, accomodation menjadi akomodasi, rhythm menjadi ritme, dan scenography menjadi senografi.

Unsur-unsur asing ini telah menambah sejumlah besar kata ke dalam bahasa Indonesia sehingga bahasa Indonesia mengalami perkembangan sesuai dengan tuntutan zaman. Dan sejalan dengan perkembangan itu muncullah masalah-

Copyright @ 2015, LITIGASI, p-ISSN: 0853-7100; e-ISSN: 2442-2274 
masalah kebahasaan. Ada kosa kata yang diserap secara utuh tanpa mengalami perubahan dan penyesuaian. Dan ada kosa kata yang diserap dengan mengalami penyesuaian-penyesuaian.

Hasil penelitian diperoleh dan tercatat asal bahasa dan jumlah katanya, antara lain:

\begin{tabular}{|l|c|}
\hline 1. Arab & 1.495 kata \\
\hline 2. Belanda & 3.280 kata \\
\hline 3. Perancis & 30 kata \\
\hline 4. Tionghoa & 290 kata \\
\hline 5. Hindi & 7 kata \\
\hline 6. Inggris & 63 kata \\
\hline 7. Parsi & 131 kata \\
\hline 8. Portugis & 677 kata \\
\hline 9. Sanskerta-Jawa Kuno & 83 kata \\
\hline 10. Tamil & \\
\hline
\end{tabular}

\section{A. Serapan Dari Istilah Hukum Belanda, Perancis Dan Jerman.}

Hukum merupakan sebagian dari kebudayaan suatu bangsa. Secara de facto bahwa setiap bangsa mempunyai kebudayaan sendiri dan juga mempunyai hukum sendiri yang berbeda dari kebudayaan dan hukum bangsa lain. Dalam tatanan hukum modern, paling tidak ada dua sistem hukum yang boleh dibilang sangat 
dominan dan memperanguhi sistem hukum dunia yakni hukum Eropa Kontinental (Belanda, Prancis) yang bercirikan civil law dan hukum Anglo Saxon (Inggris dan AS) yang bercirikan common law.

Di Indonesia terjadi perkembangan hukum nasionalnya berdasarkan asas konkordansi Belanda (pengaruh kolonialisme). Dan sampai sekarangpun, pemberlakuan hukum warisan Belanda ini tetap diakui dan masih dipakai oleh sarjana-sarjana hukum di dalam memberikan referensinya kepada dunia hukum pada umumnya. Dasar hukumnya adalah Aturan Peralihan Pasal 1 UUD 1945 (Perubahan keempat setelah amandemen UUD). Ketentuan inilah yang menyebabkan Burgerlijk Wetboek atau lebih dikenal sebagai BW (Kitab Undangundang Hukum Perdata), KUHP atau Wetboek van Strafrecht (meskipun ada perubahan-perubahan), HO (Hinder Ordonantie) dan aturan-aturan lainnya masih berlaku sampai sekarang. Belanda memang sedikit banyaknya turut memberikan saham bagi bangsa Indonesia khususnya dalam hal sistem pendidikan termasuk pendidikan hukum dan sistem hukumnya. Hal ini karena bahwa pemerintah Belanda pada yang telah menjajah bangsa Indonesia selama 3,5 abad tentu akan membawa pengaruh yang besar pada ilmu hukum sebagai suatu ilmu pengetahuan. Sebuah proses hidup dan berkembangnya sejarah suatu bangsa yakni suatu kesinambungan antara masa lalu, sekarang, dan masa yang akan datang. Salah satunya adalah masa lalu. Masa lalu sebagai suatu cerminan sejarah yang sekiranya bisa kita kaji secara bersama-sama untuk mendeskripsikan secara jelas bahwa kehadiran negara satu dengan negara lain seperti Belanda dalam

Copyright ( 2015 , LITIGASI, p-ISSN: 0853-7100; e-ISSN: 2442-2274 
kehidupan bangsa Indonesia sangat berpengaruh, baik dalam konteks praktis maupun yang lebih bersifat substantif.

Di Indonesia istilah/terminologi hukum adalah hasil serapan dari kosa kata:

1. Hukum.

Kata hukum berasal dari bahasa Arab "Hukum dan merupakan bentuk tunggal, yang selanjutnya diambil dalam bahasa Indonesia menjadi "Hukum". Di dalam pengertian hukum terkandung pengertian bertalian erat dengan pengertian yang dapat melakukan paksaan.

2. Recht

Recht berasal dari "Rectum" (bahasa latin) yang mempunyai arti bimbingan atau tuntutan, atau pemerintahan. Bertalian dengan rectum dikenal kata "Rex" yaitu orang yang pekerjaannya memberikan bimbingan atau memerintah. Rex juga dapat diartikan "Raja" yang mempunyai Regimen yang artinya kerajaan. Kata Rectum dapat juga dihubungkan dengan kata "Directum" yang artinya orang yang mempunyai pekerjaan membimbing atau mengarahkan. Kata-kata Directur atau rector mempunyai arti yang sama. Kata Recht atau bimbingan atau pemerintahan selalu didukung oleh kewibawaan. Seorang yang membimbing, memerintah harus mempunyai kewibawaan. Kewibawaan mempunyai hubungan erat dengan ketaatan oleh orang lain. Dengan demikian perkataan recht mengandung pengertian kewibawaan dan hukum atau recht itu ditaati orang yang secara sukarela. Dari kata recht tersebut timbul istilah "Gerechtigheid'Mni adalah bahasa Belanda atau "gerechtikeit"

Copyright ( 2015, LITIGASI, p-ISSN: 0853-7100; e-ISSN: 2442-2274 
dalam bahasa Jerman berarti keadilan, sehingga hukum juga mempunyai hubungan erat dengan keadilan. Jadi dengan demikian recht dapat diartikan hukum yang mempunyai dua unsur penting yaitu "kewibawaan dan keadilan"

3. Ius

Kata Ius (latin) berarti hukum, berasal dari bahasa latin "lubere" artinya mengatur atau memerintah. Perkataan mengatur dan memerintah itu mengandung dan berpangkal pokok pada kewibawaan. Selanjutnya istilah lus bertalian erat dengan "Iustitia" atau keadilan.

4. Lex

Kata lex berasal dari bahasa latin dan berasal dari kata "Lesere". Lesere artinya mengumpulkan ialah mengumpulkan orang-orang ' untuk diperintah. Jadi di sini terkandung adanya hukum ialah wibawa atau otoritas, sehingga kata Lex yang berarti hukum sangat erat hubungannya dengan perintah ( $R$. Soeroso, $2005: 24)$.

Beberapa istilah hasil serapan dalam terminologi hukum dari:

1. Bahasa Belanda

\begin{tabular}{|c|l|l|}
\hline No. & \multicolumn{1}{|c|}{ Istilah } & \multicolumn{1}{|c|}{ Makna } \\
\hline 1 & Actor Sequitur Forum Rei & gugatan harus dialamatkan pada \\
& & alamat tergugat. \\
\hline 2 & Actor Squitur Forum Sitei & gugatan harus dialamatkan pada \\
& & alamat di mana benda tidak \\
& & bergerak tersebut berada. \\
\hline
\end{tabular}

Copyright @ 2015, LITIGASI, p-ISSN: 0853-7100; e-ISSN: 2442-2274 
Available online at: http://ejournal.unpas.ac.id/index.php/litigasi

Litigasi, Vol. 16(2), 2015, 2875-2905

DOI: http://dx.doi.org/10.23969/litigasi.v16i2.37

\begin{tabular}{|c|c|c|}
\hline 3 & Akta Compromi & $\begin{array}{l}\text { klausul yang dibuat setelah timbul } \\
\text { permasalahan }\end{array}$ \\
\hline 4 & Audi Et Alterem Partem & $\begin{array}{l}\text { hakim harus mendengarkan } \\
\text { keterangan dari para pihak. }\end{array}$ \\
\hline 5 & Conservatoir Beslag & $\begin{array}{l}\text { sita jaminan terhadap barang } \\
\text { bergerak / tidak bergerak milik } \\
\text { tergugat }\end{array}$ \\
\hline 6 & $\begin{array}{l}\text { Constitue berasal dari bahasa } \\
\text { belanda Konstitusi Dader }\end{array}$ & pelaku tindak pidana \\
\hline 7 & Dader/ Doer & orang yang melakukan delik \\
\hline 8 & Dading & Perdamaian \\
\hline 9 & Derden Verzete & $\begin{array}{l}\text { perlawanan pihak ketiga yang } \\
\text { merasa mempunyai hak dan } \\
\text { kepentingan, yang secara nyata- } \\
\text { nyata telah dirugikan oleh karena } \\
\text { adanya suatu putusan pengadilan, } \\
\text { dengan cara menggugat para } \\
\text { pihak yang berperkara (gugatan } \\
\text { biasa) dapat menangguhkan } \\
\text { eksekusi hanya jika diperintahkan } \\
\text { oleh KPN }\end{array}$ \\
\hline 10 & Doenpleger/Manus/Domina & orang yang menyuruh melakukan \\
\hline
\end{tabular}

Copyright @ 2015, LITIGASI, p-ISSN: 0853-7100; e-ISSN: 2442-2274 
Available online at: http://ejournal.unpas.ac.id/index.php/litigasi

Litigasi, Vol. 16(2), 2015, 2875-2905

DOI: http://dx.doi.org/10.23969/litigasi.v16i2.37

\begin{tabular}{|c|c|c|}
\hline 11 & Droit inviolable Et Sacre & $\begin{array}{l}\text { hak yang tidak dapat diganggu } \\
\text { gugat }\end{array}$ \\
\hline 12 & Dwingen & Memaksa \\
\hline 13 & Ex Aequo Et Bono & putusan yang seadil-adilnya \\
\hline 14 & Feit & Perbuatan \\
\hline 15 & Fiat Justisia Ruat Coelum & $\begin{array}{l}\text { keadilan harus ditegakkan } \\
\text { meskipun langit runtuh }\end{array}$ \\
\hline 16 & Hak Retensi & $\begin{array}{l}\text { hak untuk menahan } \\
\text { dokumen/berkas klien oleh } \\
\text { ADVOKAT yang tidak } \\
\text { membayar/melunasi honorarium } \\
\text { yang telah disepakati }\end{array}$ \\
\hline 17 & Intervensi & $\begin{array}{l}\text { masuknya pihak ketiga yang } \\
\text { merasa mempunyai hak atau } \\
\text { kepentingan untuk turut serta } \\
\text { dalam perkara yang sedang } \\
\text { dalam proses pemeriksaan di } \\
\text { pengadilan }\end{array}$ \\
\hline 18 & Ipso Jure & $\begin{array}{l}\text { demi hukum / berdasarkan } \\
\text { hokum }\end{array}$ \\
\hline 19 & Kaukus & pertemuan antara mediator \\
\hline
\end{tabular}

Copyright @ 2015, LITIGASI, p-ISSN: 0853-7100; e-ISSN: 2442-2274 
Available online at: http://ejournal.unpas.ac.id/index.php/litigasi

Litigasi, Vol. 16(2), 2015, 2875-2905

DOI: http://dx.doi.org/10.23969/litigasi.v16i2.37

\begin{tabular}{|c|c|c|}
\hline & & $\begin{array}{l}\text { dengan salah satu pihak dalam } \\
\text { proses mediasi, tanpa dihadiri } \\
\text { oleh pihak lainnya }\end{array}$ \\
\hline 20 & Lambroso theory & character of crime \\
\hline 21 & Mededader / Madeplegen & orang yang turut melakukan \\
\hline 22 & Medeplichtigheid & Membantu \\
\hline 23 & Miranda Rule & $\begin{array}{l}\text { hak seorang tersangka untuk } \\
\text { mendapatkan penasehat hukum } \\
\text { dalam perkaranya. }\end{array}$ \\
\hline 24 & Misdriff & Kejahatan \\
\hline 25 & Mutatis Mutandis & $\begin{array}{l}\text { diakui / sah dengan perubahan- } \\
\text { perubahan yang ada }\end{array}$ \\
\hline 26 & Negative Wetelijk & $\begin{array}{l}\text { (KUHAP) pembuktian minimal } 2 \\
\text { alat bukti ditambah keyakinan } \\
\text { hakim }\end{array}$ \\
\hline 27 & Nlet Onvangkelijk Verklaard & gugatan / tuntutan tidak diterima \\
\hline 28 & $\begin{array}{l}\text { Noela Poena Sine Legi Pravia } \\
\text { Poenale }\end{array}$ & $\begin{array}{l}\text { tidak ada hukuman yang tanpa } \\
\text { didasari oleh suatu ketentuan } \\
\text { peraturan yang telah ada } \\
\text { sebelumnya. (Pasal } 1 \text { (1) KUHP) }\end{array}$ \\
\hline 29 & Noodweer & dalam keadaan terpaksa \\
\hline
\end{tabular}

Copyright (C) 2015, LITIGASI, p-ISSN: 0853-7100; e-ISSN: 2442-2274 
Available online at: http://ejournal.unpas.ac.id/index.php/litigasi

Litigasi, Vol. 16(2), 2015, 2875-2905

DOI: http://dx.doi.org/10.23969/litigasi.v16i2.37

\begin{tabular}{|c|c|c|}
\hline 30 & Notoir Feit & $\begin{array}{l}\text { hal yang telah diketahui dan } \\
\text { dinyakini kebenarannya oleh } \\
\text { umum tidak perlu dibuktikan } \\
\text { lagi. }\end{array}$ \\
\hline 31 & Onslag & lepas dari segala tuntutan hukum \\
\hline 32 & Onsplitbar' Aveu & $\begin{array}{l}\text { suatu pengakuan tidak dapat } \\
\text { dipisahkan-pisahkan }\end{array}$ \\
\hline 33 & Overmacht & $\begin{array}{l}\text { keadaan yang memaksa (tidak } \\
\text { bias dielakan) }\end{array}$ \\
\hline 34 & Overtrading & Pelanggaran \\
\hline 35 & Pacta Sunt Servanda & $\begin{array}{l}\text { perjanjian merupakan sebagai } \\
\text { undang-undang bagi yang } \\
\text { membuatnya } \\
\text { KUHPerdata "semua persetujuan } \\
\text { yang dibuat secara sah berlaku } \\
\text { sebagai undang-undang bagi } \\
\text { mereka yang membuatnya...." }\end{array}$ \\
\hline 36 & Pactum De Compromitendo & $\begin{array}{l}\text { klausul penyelesaian arbitrase } \\
\text { yang dibuat sebelumnya. }\end{array}$ \\
\hline 37 & Philosophische grondslag & norma dasar yang bersifat filsafati \\
\hline 38 & Point De Ibtern Point Atim & tidak ada sengketa tidak ada \\
\hline
\end{tabular}

Copyright @ 2015, LITIGASI, p-ISSN: 0853-7100; e-ISSN: 2442-2274 
Available online at: http://ejournal.unpas.ac.id/index.php/litigasi

Litigasi, Vol. 16(2), 2015, 2875-2905

DOI: http://dx.doi.org/10.23969/litigasi.v16i2.37

\begin{tabular}{|c|c|c|}
\hline & & perkara \\
\hline 39 & Prerogasi & $\begin{array}{l}\text { mengajukan suatu sengketa } \\
\text { berdasarkan persetujuan } \\
\text { kesepakatan para pihak kepada } \\
\text { hakim tingkat pengadilan yang } \\
\text { lebih tinggi, yang seharusnya } \\
\text { tidak berwenang menangani } \\
\text { perkara tersebut (ac.perdata) }\end{array}$ \\
\hline 40 & $\begin{array}{l}\text { Res Judikata Pro Veritate } \\
\text { Habitur }\end{array}$ & $\begin{array}{l}\text { putusan hakim dianggap benar } \\
\text { selama belum dibuktikan atau } \\
\text { putusan sebaliknya. }\end{array}$ \\
\hline 41 & Revindicatoir Beslag & $\begin{array}{l}\text { sita terhadap barang bergerak } \\
\text { milik penggugat yang dikuasai } \\
\text { oleh tergugat. }\end{array}$ \\
\hline 42 & Saksi Verbalisan & $\begin{array}{l}\text { saksi yang melakukan } \\
\text { pemeriksaan ditingkat penyidikan }\end{array}$ \\
\hline 43 & Saksi a Charge & $\begin{array}{l}\text { saksi yang memberatkan } \\
\text { terdakwa }\end{array}$ \\
\hline 44 & Saksi Ade Charge & $\begin{array}{l}\text { saksi yang menguntungkan } \\
\text { terdakwa }\end{array}$ \\
\hline 45 & Sans Prejudice & $\begin{array}{l}\text { surat yang tidak dapat dijadikan } \\
\text { alat bukti, dibuka, dalam }\end{array}$ \\
\hline
\end{tabular}

Copyright (C) 2015, LITIGASI, p-ISSN: 0853-7100; e-ISSN: 2442-2274 
Available online at: http://ejournal.unpas.ac.id/index.php/litigasi

Litigasi, Vol. 16(2), 2015, 2875-2905

DOI: http://dx.doi.org/10.23969/litigasi.v16i2.37

\begin{tabular}{|c|c|c|}
\hline & & persidangan \\
\hline 46 & Sumpah Decisoir & $\begin{array}{l}\text { sumpah pemutus / akhiri } \\
\text { sengketa / yang diminta oleh } \\
\text { pihak satunya terhadap pihak } \\
\text { yang lain agar diucapkan, untuk } \\
\text { menggantungkan putusan perkara } \\
\text { padanya (KUHPerdata 1929) }\end{array}$ \\
\hline 47 & Tussenkomst & menengahi (tidak memihak) \\
\hline 48 & Uit Loker & orang yang sengaja membujuk \\
\hline 49 & Uit Voor Bar Bij Voor Raad & $\begin{array}{l}\text { putusan serta merta, putusan } \\
\text { yang diputus sebelum putusan } \\
\text { akhir, yang dapat dilaksanakan } \\
\text { dahulu meskipun belum } \\
\text { berkekuatan hukum tetap }\end{array}$ \\
\hline 50 & Unus Testis Nulus Testis & $\begin{array}{l}\text { satu orang saksi bukan } \\
\text { merupakan (saksi) alat bukti (min } \\
2 \quad \text { org). 1866- } 1895 \\
\text { KUHPerdata }\end{array}$ \\
\hline 51 & Vague & Kabur \\
\hline 52 & Verband & hubungan erat \\
\hline 53 & Verkapte Vrijpraak & putusan bebas tidak murni \\
\hline
\end{tabular}

Copyright @ 2015, LITIGASI, p-ISSN: 0853-7100; e-ISSN: 2442-2274 
Available online at: http://ejournal.unpas.ac.id/index.php/litigasi

Litigasi, Vol. 16(2), 2015, 2875-2905

DOI: http://dx.doi.org/10.23969/litigasi.v16i2.37

\begin{tabular}{|c|l|l|}
\hline 54 & Voeging & menyertai (ikut salah satu pihak) \\
\hline 55 & Vrijwaring & penanggungan / pembelaan (atas \\
& permintaan biasanya tergugat) \\
\hline 56 & Vrisparaak & bebas/tidak terbukti secara sah \\
& Zaakssgevolg / Droit De Siv/f & mengikuti benda dimanapun dan \\
& & dalam tangan siapapun benda itu \\
\hline 60 & Dan lain-lain & berada \\
\hline
\end{tabular}

2. Bahasa Perancis

a. Abandonemen Asal kata: Bahasa Perancis abandonner yang artinya meninggalkan atau melepaskan hak. Dalam hukum tanggungan (asuransi): hak orang yang membeli asuransi (tertanggung) untuk melepaskan hak-haknya atas benda yang diasuransikannya, jika memang benda tersebut mengalami kerusakan, kepada penanggung. Dengan penyerahan ini, pihak tertanggung berhak menerima uang pertanggungan sepenuhnya dari pihak penanggung, seolah-olah benda yang diasuransikan oleh si tertanggung musnah sama sekali. Di Indonesia dan beberapa negara, hal ini hanya diberlakukan pada hukum laut: hak milik atas kapal atau barang-barang yang ditanggung

Copyright (C) 2015, LITIGASI, p-ISSN: 0853-7100; e-ISSN: 2442-2274 
Available online at: http://ejournal.unpas.ac.id/index.php/litigasi

Litigasi, Vol. 16(2), 2015, 2875-2905

DOI: http://dx.doi.org/10.23969/litigasi.v16i2.37

diserahkan kepada penanggung oleh tertanggung dengan menerima jumlah uang seluruhnya yang harus dibayar kepada tertanggung dalam hal musnahnya kapal atau barang-barang yang diasuransikan. Kemungkinan abandonemen dalam sebuah polis bursa biasanya dibatasi.

b. Abus de pouvoir :penyalahgunaan kekuasaan oleh instansi pemerintah

c. Arraignment:adalah istilah common law untuk pembacaan resmi criminal complaint di hadapan defendant, untuk memberi tahu tuduhan terhadapnya. Sebagai jawaban, ia diharapkan untuk menyatakan pengakuan, misalnya "bersalah", "tidak bersalah", peremptory plea, nolo contendere, atau alford plea.

d. Constiture: Istilah konstitusi dalam bahasa Perancis

e. Force majeure yang berarti "kekuatan yang lebih besar" adalah suatu kejadian yang terjadi di luar kemampuan manusia dan tidak dapat dihindarkan sehingga suatu kegiatan tidak dapat dilaksanakan atau tidak dapat dilaksanakan sebagaimana mestinya. Yang termasuk kategori keadaan kahar adalah peperangan, kerusuhan, revolusi, bencana alam, pemogokan, kebakaran, dan bencana lainnya yang harus dinyatakan oleh pejabat/instansi yang berwenang.

3. Bahasa Jerman

a. Bebauungsvorschriften:Zonasi hokum;

b. Gesellschaftsform:Hukum bentuk;

Copyright @ 2015, LITIGASI, p-ISSN: 0853-7100; e-ISSN: 2442-2274 
Available online at: http://ejournal.unpas.ac.id/index.php/litigasi

Litigasi, Vol. 16(2), 2015, 2875-2905

DOI: http://dx.doi.org/10.23969/litigasi.v16i2.37

c. Gesetzesbrecher:Pelanggar hokum;

d. Legates:Hukum;

e. LuxusgesetzSumptuary: hukum;

f. Ordnungswidrigkeit:Pelanggaran hukum yang ringan;

g. Personlichkeitsrecht:Hukum kepribadian;

h. Weltanschaung: berarti pandangan mendasar tentang dunia.

Konstitusi dalam bahasa jerman "vertassung" dalam ketatanegaraan

RI diartikan sama dengan Undang-Uundang Dasar.

i. Dan Iain-lain.

\section{Bahasa Latin}

a. Contitutio, constituere, Istilah konstitusi dalam bahasa latin o ex post facto, yang berarti retroaktif atau berlaku surut "dari sesuatu yang dilakukan setelahnya", adalah suatu hukum yang mengubah konsekuensi hukum terhadap tindakan yang dilakukan atau status hukum fakta-fakta dan hubungan yang ada sebelum suatu hukum diberlakukan atau diundangkan. Dalam kaitannya dengan hukum kriminal, hukum retroaktif dapat diterapkan pada suatu tindakan yang legal atau memiliki hukuman yang lebih ringan sewaktu dilakukan. Penerapan hukum ini dapat mengubah aturan bukti-bukti yang ditemukan untuk memperbesar kemungkinan pemberian hukuman pada seorang terdakwa. Sebaliknya, penerapan hukum jenis

Copyright (C) 2015, LITIGASI, p-ISSN: 0853-7100; e-ISSN: 2442-2274 
Available online at: http://ejournal.unpas.ac.id/index.php/litigasi

Litigasi, Vol. 16(2), 2015, 2875-2905

DOI: http://dx.doi.org/10.23969/litigasi.v16i2.37

ini dapat pula mengurangi atau bahkan membebaskan seeing terhukum.

b. Ius sanguinis atau jus songu/n/sadalah hak kewarganegaraan yang diperoleh seseorang (individu) berdasarkan kewarganegaraan ayah atau ibu biologisnya. Kebanyakan bangsa yang memiliki sejarah panjang menerapkan asas ini, seperti negara-negara di Eropa dan Asia Timur.

c. Ius soli atau jus soli (bahasa Latin untuk "hak untuk wilayah") adalah hak mendapatkan kewarganegaraan yang dapat diperoleh bagi individu berdasarkan tempat lahir di wilayah dari suatu negara. Ini berlawanan dengan

d. Iex soli, biasanya sebuah peraturan praktikal pemerolehan nasionalitas atau kewarganegaraan sebuah negara oleh kelahiran di wilayah tersebut diberikan oleh sebuah hukum turunan. Banyak negara memberikan lex soli tertentu, dalam aplikasi dengan jus soli yang bersangkutan, dan aturan ini yang paling umum untuk memperoleh nasionalitas. Sebuah pengecualian lex soli diterapkan bila anak yang dilahirkan orang tuanya adalah seorang diplomat dari negara lain, yang dalam misi di negara bersangkutan. Namun, banyak negara memperketat lex soli dengan mengharuskan paling tidak salah satu orang tua harus memiliki warga negara yang bersangkutan atau izin tinggal resmi lainnya pada saat kelahiran anak tersebut. Alasan utama

Copyright @ 2015, LITIGASI, p-ISSN: 0853-7100; e-ISSN: 2442-2274 
Available online at: http://ejournal.unpas.ac.id/index.php/litigasi

Litigasi, Vol. 16(2), 2015, 2875-2905

DOI: http://dx.doi.org/10.23969/litigasi.v16i2.37

menerapkan aturan tersebut adalah untuk membatasi jumlah orang bepergian ke negara lain dengan tujuan mendapatkan kewarganegaraan untuk seorang anak. Ius soli umum di negara-negara di Amerika dan di tempat lain yang ingin mengembangkan dan meningkatkan penduduk mereka.

e. Mala in se atau malum in se (sering pula disebut sebagai mala per se) adalah istilah bahasa Latin yang mengacu kepada suatu perbuatan yang dianggap sebagai sesuatu yang jahat bukan karena diatur demikian atau dilarang oleh Undang-Undang, melainkan karena pada dasarnya bertentangan dengan kewajaran, moral dan prinsip umum masyarakat beradab.

f. Mala prohibita atau malum prohibitum, adalah istilah bahasa Latin yang mengacu kepada perbuatan yang tergolong kejahatan karena diatur demikian oleh Undang-Undang. Tindak Pidana Ekonomi atau white collar crimes dapat diambil sebagai contoh mala prohibita. Di lain pihak, terdapat apa yang disebut Mala in se atau malum in se (sering pula disebut sebagai mala per se) adalah istilah bahasa Latin yang mengacu kepada suatu perbuatan yang dianggap sebagai sesuatu yang jahat bukan karena diatur demikian atau dilarang oleh UndangUndang, melainkan karena pada dasarnya bertentangan dengan kewajaran, moral dan prinsip umum masyarakat beradab.

g. Per Procurationem(PP) : atas nama

Copyright (C) 2015, LITIGASI, p-ISSN: 0853-7100; e-ISSN: 2442-2274 
Available online at: http://ejournal.unpas.ac.id/index.php/litigasi

Litigasi, Vol. 16(2), 2015, 2875-2905

DOI: http://dx.doi.org/10.23969/litigasi.v16i2.37

h. Dan lain-lain (www.muhammadarifudin.blogspot.com).

\section{B. Serapan Dari Anglo Saxon (Terminologi Hukum Inggris Dan Amerika)}

Dimulainya abad globalisasi dimana bahasa Inggris (Amerika) menjadi bahasa yang sangat berpengaruh terutama karena menjadi bahasa pengantar dalam urusan politik maupun ekonomi, bahkan menjadi bahasa untuk menaikkan citra seseorang bahwa orang tersebut terlihat lebih intelek, berbahasa gaul atau terpelajar. Dan sudah dimulai pula pengaruh bahasa China yang banyak dipergunakan/dipelajari disekolah-sekolah karena Negara China yang maju pesat dalam peraturan baik politik maupun dagang di dunia.

Karena pengaruh bahasa Inggris ini sangat dominan, serapan bahasa dari hukum Eropa Kontinental (Belanda, Perancis/Jerman) sedikit berkurang, bahkan banyak pelajar-pelajar atau sarjana-sarjana hukum yang sudah tidak lagi fasih mengucapkan kata serapan dari bahasa Belanda, Perancis atau Jerman.

Di bawah ini beberapa serapan bahasa Inggris dalam terminologi hukum yang sudah biasa dipergunakan dan didengar di Indonesia :

1. Check and balance: sistem pemerintahan yang memakai perimbangan dalam melaksanakan Ajaran Trias Politika;

2. Constitution Istilah konstitusi berasal dari bahasa Inggris;

3. Crimes against conscience. Terdapat pandangan mengenai penerapan kedua istilah tersebut. Jeremy Bentham menyatakan bahwa suatu tindakan yang tergolong mala in se, tidak dapat berubah (immutable),

Copyright @ 2015, LITIGASI, p-ISSN: 0853-7100; e-ISSN: 2442-2274 
Available online at: http://ejournal.unpas.ac.id/index.php/litigasi

Litigasi, Vol. 16(2), 2015, 2875-2905

DOI: http://dx.doi.org/10.23969/litigasi.v16i2.37

artinya dalam ruang manapun dan waktu tertentu kapanpun, tindakan tersebut tetap dianggap sebagai perbuatan jahat dan dilarang oleh Undang-undang. Sedangkan suatu tindakan yang tergolong mala prohibita, dapat berubah (not immutable), artinya dalam ruang dan waktu tertentu yang berbeda, tindakan tersebut dapat saja tidak lagi dianggap sebagai perbuatan jahat dan dilarang oleh Undang-Undang. Menurut Hans Kelsen dalam General Theory of Law and State, kedua pembedaan tersebut hanya terdapat pada teori tradisional hukum pidana. Lebih lanjut dinyatakan bahwa suatu perbuatan mungkin merupakan suatu delik di suatu komunitas masyarakat, namun tidak demikian dalam komunitas masyarakat yang lain karena perbedaan nilai moral yang dianut oleh masing-masing komunitas. Dan oleh karena suatu perbuatan dapat dikatakan sebagai suatu delik hanya ketika telah dilekati oleh sanksi hukum oleh Undang-Undang, maka semua delik adalah mala prohibita. Dengan kata lain, suatu perbuatan yang dianggap sebagai sesuatu yang jahat menurut hati nurani seseorang (mala in se) tetaplah bukan merupakan delik, jika atasnya tidak dilekati sanksi (hukuman/pidana). Dasar negara sesungguhnya sama dengan ideologi negara, dasar falsafat kenegaraan atau pandangan dasar kenegaraan.

4. Ideology (Inggris) dan Ideologi (Indonesia), artinya ajaran atau teori yang merupakan hasil pemikiran mendalam (pemikiran filsafati) mengenai dunia dan kehidupan di dunia, termasuk kehidupan bernegara

Copyright ( 2015, LITIGASI, p-ISSN: 0853-7100; e-ISSN: 2442-2274 
Available online at: http://ejournal.unpas.ac.id/index.php/litigasi

Litigasi, Vol. 16(2), 2015, 2875-2905

DOI: http://dx.doi.org/10.23969/litigasi.v16i2.37

di dalamnya, yang dijadikan pedoman dasar dalam mengatur dan memelihara kehidupan bersama dalam suatu negara.

5. Legal Crime, sebuah kejahatan hukum / kejahatan, (mala prohibita) adalah dimana masyarakat memutuskan secara keseluruhan, bahwa kejahatan tersebut menjadi pelanggaran undang-undang yang melindungi kepentingan masyarakat itu. Sebuah contoh dari, "mala prohibita," undang-undang lalu lintas. Hukum dan pembatasan yang diundangkan untuk melindungi kepentingan publik.

6. Natural crime, dalam terminologi bahasa Inggris. istilah ini sudah sering dipergunakan dalam konteks hukum Indonesia, dan dalam beberapa tindak pidana seperti tindak pidana terorisme, sering pula digolongkan ke dalam kejahatan terhadap hati nurani (crimes against conscience). Beberapa contoh perbuatan yang termasuk mala in se atau malum in se atau mala per se antara lain adalah pembunuhan, perkosaan, pencurian, perampokan. Menurut Jeremy Bentham, suatu tindakan yang tergolong mala in se, tidak dapat berubah (immutable), artinya dalam ruang manapun dan waktu tertentu kapanpun, tindakan tersebut tetap dianggap sebagai perbuatan jahat dan dilarang oleh Undang-Undang. Contoh, "mala in se," akan menjadi pembunuhan atau kejahatan terhadap anak-anak. Diasumsikan kita semua harus inheren memahami bahwa kejahatan tersebut salah. Kejahatan seperti ini sering dipandang

Copyright @ 2015, LITIGASI, p-ISSN: 0853-7100; e-ISSN: 2442-2274 
Available online at: http://ejournal.unpas.ac.id/index.php/litigasi

Litigasi, Vol. 16(2), 2015, 2875-2905

DOI: http://dx.doi.org/10.23969/litigasi.v16i2.37

sebagai tindakan kejahatan.

Beberapa contoh tambahan serapan bahasa Inggris dalam terminologi hukum :

1. Access to Justice: Sama rata sama rasa;

2. Act, Law: Undang-undang;

3. Acting/on duty: Plh (pelaksana harian);

4. Ad interim/Caretaker/Acting official:Pit. (pelaksana tugas);

5. Affirmative Actions: Diskriminasi Positif;

6. Amendments: Amandemen;

7. Attorney General:Jaksa Agung;

8. Chapter/Article: Pasal;

9. Clause/Verse: Ayat;

10. Constitution of the Republic of Indonesia: Undang-Undang Dasar Negara Republik Indonesia;

11. Contempt of court:Perbuatan tercela/penghinaan/Pertentangan hokum;

12. District Attorney: Jaksa Wilayah;

13. Government Ordinance:Peraturan Pemerintah;

14. Investigation \& Interrogation Report: Berita Acara Pemeriksaan (BAP);

15. Judicial Review: Uji Materil/PK;

16. Justice Collaborator:Saksi pelaku yang bekerja sama;

17. Legal Standing: Kedudukan Hukum;

18. Ministerial Decreed Dekrit: Keputusan Menteri;

Copyright (C) 2015, LITIGASI, p-ISSN: 0853-7100; e-ISSN: 2442-2274 
Available online at: http://ejournal.unpas.ac.id/index.php/litigasi

Litigasi, Vol. 16(2), 2015, 2875-2905

DOI: http://dx.doi.org/10.23969/litigasi.v16i2.37

19. On behalf of : Atas nama;

20. Presidential Decreed Dekrit: Keputusan Presiden;

21. Presumption of Innocence:Praduga Tak Bersalah;

22. Senate Hearing: Sidang Senat;

23. Shifting burden of proof: Pembuktian Terbalik;

24. State Gazette, Statute Book: Lembaran Negara;

25.Stolen Asset Recovery: Pengembalian aset tindak pidana;

26.Threshold: Ambang batas;

27. Whistle blower :Pelapor Tindak Pidana/Perdata(www. ind.proz.com). 
Available online at: http://ejournal.unpas.ac.id/index.php/litigasi

Litigasi, Vol. 16(2), 2015, 2875-2905

DOI: http://dx.doi.org/10.23969/litigasi.v16i2.37

\section{IV.SIMPULAN DAN SARAN}

\section{A. SIMPULAN}

1. Penyerapan istilah asing dapat saja diterima, dan tidak dapat dicegah antara lain demi kemudahan pengalihan antar-bahasa dan keperluan masa depan, terutama bahasa Inggris yang menjadi bahasa internasional. Saat ini sedang digalakkan di dunia pendidikan yaitu bahasa China yang mungkin kelak akan seperti bahasa lainnya banyak mempengaruhi bahasa Indonesia.

2. Bahwa hubungan internasional dengan bangsa lain sangat dibutuhkan untuk pembangunan bangsa, baik hubungan kenegaraan maupun bisnis dimana akan muncul istilah-istilah baru yang tidak dapat secara langsung diterjemahkan ke dalam bahasa Indonesia, agar supaya tidak ada salah pengertian, penafsiran atau presepsi.

3. Bahasa serapan harus tetap dipergunakan dalam dunia pendidikan agar para siswa/mahasiswa dapat mengerti dan mempergunakannya kelak baik di dunia pendidikan berikutnya atau di dunia yang berhubungan dengan bangsa lain, di bidang hukum, ekonomi dan politik.

4. Bahasa serapan tidak akan merusak bahasa Indonesia, tetapi justru menambah perbendaharaan kosa kata dan istilah-istilah dalam bahasa Indonesia.

Copyright (C) 2015, LITIGASI, p-ISSN: 0853-7100; e-ISSN: 2442-2274 
Available online at: http://ejournal.unpas.ac.id/index.php/litigasi

Litigasi, Vol. 16(2), 2015, 2875-2905

DOI: http://dx.doi.org/10.23969/litigasi.v16i2.37

5. Oleh karena itu penggunaan bahasa serapan asing dalam terminologi hukum Indonesia menjadi hal yang sah-sah saja biasa dan bahkan justru memang seharusnya dipergunakan.

\section{B. SARAN}

1. Oleh karena istilah dan terminologi hukum itu hanya dipahami oleh para pakar hukum saja, maka disarankan agar istilah dan terminologi hukum itu disesuaikan dengan bahasa Indonesia pada umumnya.

2. Agar bahasa hukum hasil serapan dari bahasa asing disesuaikan dengan kaidah bahasa Indonesia.

Copyright @ 2015, LITIGASI, p-ISSN: 0853-7100; e-ISSN: 2442-2274 


\section{DAFTAR PUSTAKA}

\section{BUKU}

Arifin, W. dan Soemargono, F, 1991, Kamus Perancis Indonesia, Jakarta, Penerbit PT Gramedia Pustaka Utama.

Departemen Pendidikan dan Kebudayaan, 1999, Kamus Besar Bahasa Indonesia, Jakarta, Balai Pustaka Jakarta.

Dictionnaires de Robert, Santosa, 2008, Pulau Jawa Pernah di Bawah Kekuasaan Perancis.

Hilman Hadikusuma, 1983, Bahasa Hukum Indonesia.

H. Ridwan Syahrani, 2014, Kata-Kata Kunci Mempelajari Ilmu Hukum, Bandung, Edisi ke 2, PT Alumni.

J.D. Parera, 1987, Studi Linguistik Umum dan Historis Bandingan, Jakarta, Penerbit Erlangga.

Panitia Pengembangan Bahasa Indonesia, 2008, Pedoman Umum Pembentukan Istilah, Jakarta, Pusat Bahasa Departemen Pendidikan Nasional.

Pengindonesiaan Nama dan Kata Asing, Jakarta, Cetakan Ketiga, Balai pustaka Utama.

Soeroso, 2005, Pengantar Ilmu Hukum, Jakarta, Cetakan kelima, Sinar Grafika.

Robert. P, 2006, Le Petit Robert de la langue francaise, Paris, Nouvelle Edition.

Yayat Sudaryat, 2008, Makna dalam Wacana, Prinsip-prinsip Semantik dan Pragmatik, Bandung, CV. Yrama Widya.

\section{MAKALAH}

Bahasa Indonesia, Edisi Keempat, Jakarta, Departemen Pendidikan Nasional.

Barus, Sanggup, 2011 ,Medan, Diktat, Seminar.

Tim Penyusun Pusat Pembinaan dan Pengembangan Bahasa, 2007, Pedoman.

Tim Redaksi Kamus Besar Bahasa Indonesia Pusat Bahasa, 2008, Kamus Besar.

Copyright (C) 2015, LITIGASI, p-ISSN: 0853-7100; e-ISSN: 2442-2274 
Available online at: http://ejournal.unpas.ac.id/index.php/litigasi

Litigasi, Vol. 16(2), 2015, 2875-2905

DOI: http://dx.doi.org/10.23969/litigasi.v16i2.37

\section{WEBSITE}

http://id.wikipedia.org/wiki/Bahasa Indonesia

http://muhammadarifudin.blogspot.com/2012/09/daftar-istilah-hukum.html

http://odhepriyamona.wordpress.com/2009/10/20/bahasa-indonesia-dan-eraglobalisasi/

http://silviarasyid.blogspot.com/2010/04/pengaruh-penerapan-Penggunaan bahasa.html Gramedia Pustaka Utama.

Keraf, G. 1984. Linguistik Bandingan Historis. Jakarta: Penerbit PT Gramedia (ridalaksana, H. 2001. Kamus Linguistik. Edisi Ketiga. Jakarta: Penerbit PT lelalui laman $<$ http://rn.kompas.com $>$. Diakses pada tanggal 28 November 2009.

Oxford Advanced Learner's Dictionary - 8th Edition 2012. http://ind.proz.com.

Dan berbagai sumber lainnnya.

Copyright @ 2015, LITIGASI, p-ISSN: 0853-7100; e-ISSN: 2442-2274 